\title{
Superparamagnetic Bifunctional Bisphosphonates Nanoparticles: A Potential MRI Contrast Agent for Osteoporosis Therapy and Diagnostic
}

\author{
Y. Lalatonne, ${ }^{1,2}$ M. Monteil, ${ }^{1}$ H. Jouni, ${ }^{1}$ J. M. Serfaty, ${ }^{3}$ O. Sainte-Catherine, ${ }^{1}$ N. Lièvre, ${ }^{4}$ \\ S. Kusmia, ${ }^{5}$ P. Weinmann, ${ }^{2}$ M. Lecouvey, ${ }^{1}$ and L. Motte ${ }^{1}$ \\ ${ }^{1}$ Laboratoire CSPBAT, C2B, FRE 3043 CNRS, Université Paris 13, 93017 Bobigny Cedex, France \\ ${ }^{2}$ Service de Médecine Nucléaire, Hôpital Avicenne, APHP, 93009 Bobigny Cedex, France \\ ${ }^{3}$ Service de Radiologie, Hôpital Bichat, APHP, U 698 ISERM, Université Paris 7, 75877 Paris Cedex 18, France \\ ${ }^{4}$ UPRES 3410 Biothérapies Bénéfices et Risques, Université Paris 13, 93017 Bobigny Cedex, France \\ ${ }^{5}$ Plateforme d'IRM du Petit Animal, U 970 INSERM, Université Paris 5, 75908 Paris Cedex 10, France \\ Correspondence should be addressed to Y. Lalatonne, yoann.lalatonne@avc.aphp.fr
}

Received 14 January 2010; Revised 3 March 2010; Accepted 19 April 2010

Academic Editor: Annie Kung

Copyright (๑) 2010 Y. Lalatonne et al. This is an open access article distributed under the Creative Commons Attribution License, which permits unrestricted use, distribution, and reproduction in any medium, provided the original work is properly cited.

A bone targeting nanosystem is reported here which combined magnetic contrast agent for Magnetic Resonance Imaging (MRI) and a therapeutic agent (bisphosphonates) into one drug delivery system. This new targeting nanoplatform consists of superparamagnetic $\gamma \mathrm{Fe}_{2} \mathrm{O}_{3}$ nanoparticles conjugated to 1,5-dihydroxy-1,5,5-tris-phosphono-pentyl-phosphonic acid (diHMBPs) molecules with a bisphosphonate function at the outer of the nanoparticle surface for bone targeting. The as-synthesized nanoparticles were evaluated as a specific MRI contrast agent by adsorption study onto hydroxyapatite and MRI measurment. The strong adsorption of the bisphosphonates nanoparticles to hydroxyapatite and their use as MRI T2* contrast agent were demonstrated. Cellular tests performed on human osteosarcoma cells (MG63) show that $\gamma \mathrm{Fe}_{2} \mathrm{O}_{3} @$ di-HMBP hybrid nanomaterial has no citoxity effect in cell viability and may act as a diagnostic and therapeutic system.

\section{Introduction}

Bisphosphonates exhibits a powerful binding affinity to bones and are routinely used for treatment in bone resorption and other bone disorders like Paget's disease, osteoporosis, or tumor induced osteolysis [1]. The binding to bone mineral depends upon the P-C-P structure and is enhanced by including a hydroxyl group (hydroxy methylene bisphosphonate, called HMBP in the text). This was probably due to tridendate binding hydroxyl substituted bisphosphonates to calcium. In contrast, bisphosphonates lacking a hydroxyl group, that provide a bidendate binding to calcium crystals, had significantly lower binding affinities [2]. Hence HMBP molecules, such as Alendronate (4-amino1-hydroxybutylidene bisphosphonic acid), inhibit osteoclastmediated bone resorption [3]. With the recent developments in magnetic resonance, in vivo studies showed that patients with, and without, osteoroporotic fractures could better be separated with parameters of bone architecture obtained by MRI than BDM [4]. For molecular imaging, the use of nanoparticles emerge as very exiting nanoobjects in that many functionalities can be added to the surface of the particle. More specifically, superparamagnetic iron oxide [5] (SPIO, hydrodynamic diameter $>50 \mathrm{~nm}$ ) and ultrasmall superparamagnetic iron oxide (USPIO, hydrodynamic diameter $<50 \mathrm{~nm}$ ) particles have been introduced as an MRI contrast agent after the gadolinium chelates and appear to be currently a more relevant agent than Gd chelates due to the high MR signal per unit of metal. As these particles are made of thousands iron atoms, they defeat the inherent low contrast agent sensitivity of MRI and thus can be detected at micromolar concentration of iron. Moreover the iron ions are much less toxic than the gadolinium ones and can be reused or recycled by cells using normal 
biochemical pathways for iron metabolism $[6,7]$. Our previous studies have shown that bisphosphonate such as 1phenyl-1-hydroxymethylene-1,1-phosphonic acid (HMBP$\mathrm{COOH}$ ) [8] or 1-hydroxy-2-(imidazol-1-yl)ethylidene-1,1bisphosphonic acid (zoledronate) [9] act as very efficient ligand for iron oxide nanoparticles. In the case of quaternary ammonium bisphosphonate coated iron oxide nanocrystals, it has been shown that this hybrid nanocrystals [10] presented adequate performance for blood remanance and weak liver capture. No significant desorption of the coating molecules was observed on steel plates. In recent work [11] it has been demonstrated that pretreatment of metal alloy surface with an aqueous polyallylamine bisphosphonate solution (BP-... NH $\mathrm{NH}_{2}$ ) result in the formation of a molecular bisphophonate layer that permit the attachment via the amine terminated function of vector binding agent for therapeutic gene delivery. After 30 day incubation, the layer is not altered indicating that a mechanism of desorption reabsorption of BP molecules seems to be highly unlikely. In this article, an innovative approach is presented, leading to the optimization of the nanoparticle structure to achieve selective targeting for osteoporosis imaging and therapy. Superparamagnetic nanoparticle surface are passivated using a bifunctional passivating agent such as 1,5-dihydroxy-1,5,5tris-phosphono-pentyl-phosphonic acid (call di-HMBP in the text, Scheme 1). One HMBP function complexes the nanocrystal surface and the other one at the outer surface allows bone targeting. A stable ferrofluid $\left(\gamma \mathrm{Fe}_{2} \mathrm{O}_{3} @\right.$ diHMBP) is obtained on large concentration and $\mathrm{pH}$ range. The large numbers of HMBP functionalities on the magnetic core of the particle have a strong affinity for hydroxyapatite and can be used for bone targeting. The feasibility of such process is demonstrated by the complexation of the hybrid nanomaterial to calcium ions and hydroxyapatite and imaged using MRI.

\section{Materials and Methods}

2.1. Materials and Reagent. IR spectra were recorded on a Thermo Electron Corporation Nicolet 380 FTIR ( $\mathrm{KBr}$ pellet). UV-visible spectra were recorded on a Varian Cary 50 Scan UV-Visible spectrophotometer. Transmission electron microscopy (TEM) measurements were carried out using a Philips CM10. ${ }^{1} \mathrm{H}-\mathrm{NMR}$ spectra were obtained on a Varian Gemini spectrometer at $200 \mathrm{MHz}$ with chemical shifts being reported as ppm from trimethylsilane as internal standard. The size and the zeta potential of the nanocomplex were determined by dynamic laser light scattering (DLS) on a Nano-ZS (Red Badge) ZEN 3600 device (Malvern Instruments, Malvern, UK. All chemicals products used for nanoparticles and bisphosphonate molecules were purchased from Sigma-Aldrich (St Louis, MO). Millipore $\mathrm{H}_{2} \mathrm{O}$ was employed for the preparation of all aqueous solutions.

2.2. Synthesis of (1,5-Dihydroxy-1,5,5-Tris-Phosphono-Pentyl)-Phosphonic Acid [12] (Di-HMBPs). In a $50 \mathrm{~mL}$ roundbottom three-neck flask equipped with a thermometer, glutaryl chloride $(18 \mathrm{mmol})$ was added dropwise, under argon, at $-5^{\circ} \mathrm{C}$, to tris(trimethylsilyl) phosphite $(72 \mathrm{mmol})$. When addition was completed, reaction mixture was allowed to stand at room temperature for 1 hour. The evolution of the reaction was monitored by ${ }^{31} \mathrm{P}\{1 \mathrm{H}\} \mathrm{NMR}$. Then, volatile fractions were evaporated under reduced pressure ( 0.1 Torr) before methanolysis $(20 \mathrm{~mL})$. After evaporation, crude products were precipitated in diethylether and lyophilized. The pure product was obtained in $95 \%$ yield. ${ }^{31} \mathrm{P}$ NMR $\left\{{ }^{1} \mathrm{H}\right\}$ $\left(161.9 \mathrm{MHz}, \mathrm{D}_{2} \mathrm{O}\right) \delta 19.3,{ }^{1} \mathrm{H}$ NMR $\left(400.1 \mathrm{MHz}, \mathrm{D}_{2} \mathrm{O}\right) \delta$ 1.78-2.05 (m, 6H, C(OH)- $\left.\left(\mathrm{CH}_{2}\right)_{3}-\mathrm{C}(\mathrm{OH})\right),{ }^{13} \mathrm{C}$ NMR $\left\{{ }^{1} \mathrm{H}\right\}$ $\left(100.6 \mathrm{MHz}, \mathrm{D}_{2} \mathrm{O}\right) \delta 18.1\left(-\mathrm{CH}_{2}-\mathrm{CH}_{2}-\mathrm{CH}_{2}-\right), 34.0\left(-\mathrm{CH}_{2}-\right.$ $\left.\mathrm{CH}_{2}-\mathrm{CH}_{2}-\right), 73.2\left(\mathrm{t},{ }^{1} \mathrm{~J}_{\mathrm{P}-\mathrm{C}}=143.7 \mathrm{~Hz}, \mathrm{P}-\mathrm{C}(\mathrm{OH})-\mathrm{P}\right)$.

2.3. Synthesis of $\gamma \mathrm{Fe}_{2} \mathrm{O}_{3} @ D i-H M B P \quad$ Nanocrystals. To prepare noncoated $\gamma \mathrm{Fe}_{2} \mathrm{O}_{3}$ particles, the first step is to add a solution of dimethylamine $40 \%$ in water $\left(\left(\mathrm{CH}_{3}\right)_{2} \mathrm{NH}, 10.5 \mathrm{~mL}\right)$ to an aqueous micellar solution of ferrous dodecyl sulfate $\left(\mathrm{Fe}(\mathrm{DS})_{2}\right)\left(0.61 \mathrm{~g}, 10^{-3} \mathrm{~mol}\right)$. The solution is stirred vigorously for 2 hours at $28.5^{\circ} \mathrm{C}$ and the resulting precipitate of uncoated nanocrystals is isolated from the supernatant by centrifugation. In the second step, this precipitate is washed with an acidic solution $(\mathrm{HCl}$ $10^{-1} \mathrm{~mol} \cdot \mathrm{L}^{-1}$ ) and a solution of di-HMBPs molecules ( $n=10^{-4} \mathrm{~mol}$ in $30 \mathrm{~mL}$ of water) is added. The solution is stirred for two hours at room temperature. The precipitate that appears is washed with an acidic solution $(\mathrm{HCl}$ $\left.10^{-1} \mathrm{~mol} \cdot \mathrm{L}^{-1}\right)$. Free HMBP are isolated from the coated particles thanks to a magnetic field and by centrifugation. The magnetic nanocrystals coated with di-HMBP molecules are dispersed in water. The initial $\mathrm{pH}$ is equal to 4 and then progressively increased to $\mathrm{pH} 7.4$ by addition of sodium hydroxide $\mathrm{NaOH}\left(10^{-1} \mathrm{~mol} \cdot \mathrm{L}^{-1}\right)$. The iron concentration is deduced from UV-vis absorption.

2.4. Nanocrystal Surface Characterization. FTIR spectroscopy is used to demonstrate nanocrystal surface complexation via phosphonate groups. The average number of molecules per nanocrystal is deduced with ${ }^{31} \mathrm{P}$ NMR spectroscopy. A range of concentrations of free di-HMBP $\left(\mathrm{NMR}{ }^{31} \mathrm{P}\{1 \mathrm{H}\}(80.9 \mathrm{MHz}): 19.17 \mathrm{ppm}\right.$ solution added with $\mathrm{NaH}_{2} \mathrm{PO}_{4}$ (in capillary, $10^{-1} \mathrm{~mol} \cdot \mathrm{L}^{-1}$; NMR ${ }^{31} \mathrm{P}\{1 \mathrm{H}\}$ $(80.9 \mathrm{MHz}): 0 \mathrm{ppm})$ was prepared for calibration. The di-HMBP molecules are removed from magnetic $\gamma \mathrm{Fe}_{2} \mathrm{O}_{3}$ nanoparticles by addition of sodium hydroxide $\mathrm{NaOH}$ $\left(1 \mathrm{~mol} \cdot \mathrm{L}^{-1}\right)$ in order to avoid shifting of the ${ }^{31} \mathrm{P}$ NMR signal. The supernatant is analyzed with ${ }^{31} \mathrm{P}$ NMR and the concentration (number of molecules per nanocrystal) of diHMBP into the sample is deduced from this calibration plot.

2.5. Analysis of the Size and Surface Charges of the $\gamma \mathrm{Fe}_{2} \mathrm{O}_{3} @ D i$-HMBP Nanocrystals. The mean particle size was determined by transmission electron microscopy. Colloid suspensions were deposited directly onto a carboncoated copper grid. The size and the zeta potential of the nanocomplex was determined by dynamic laser light scattering (DLS) on a Nano-ZS (Red Badge) ZEN 3600 device (Malvern Instruments, Malvern, UK. Each sample was 


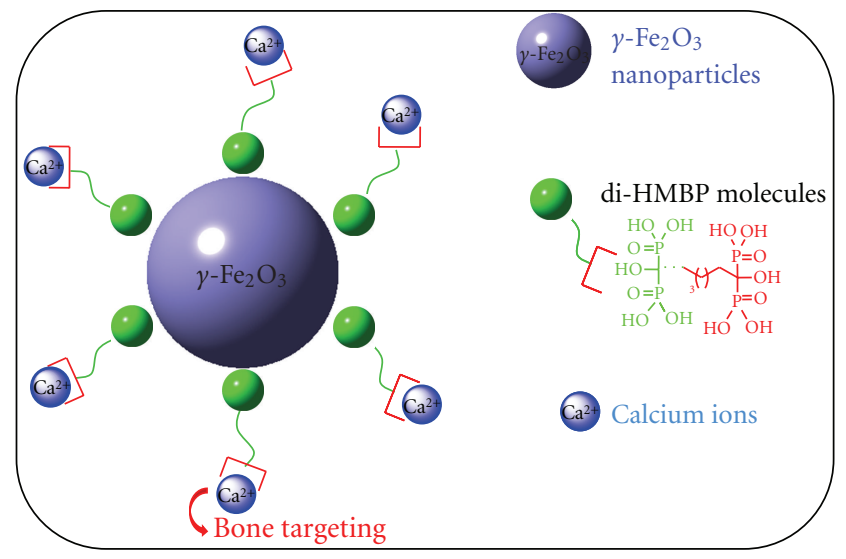

Scheme 1: Superparamagnetic $\gamma \mathrm{Fe}_{2} \mathrm{O}_{3} @$ di-HMBPs for bone targeting.

analyzed at room temperature with diluted ferrofluid $([\mathrm{Fe}]=$ $\left.5 \cdot 10^{-4} \mathrm{~mol} \cdot \mathrm{L}^{-1}\right)$ at $\mathrm{pH}=7.4$.

2.6. Calcium Complexometric Titration. Standard procedures with Eriochrome black $T$ (EBT) was used to quantify the amount of calcium ions in solution. The EBT was mixed to $\gamma \mathrm{Fe}_{2} \mathrm{O}_{3} @$ di-HMBP (or free di-HMBP) aqueous solution $\left([\mathrm{Fe}]=1,47 \cdot 10^{-2} \mathrm{~mol} \cdot \mathrm{L}^{-1}\right)$ at $\mathrm{pH} 10$. Then this solution is titrated with calcium solution $\left(\left[\mathrm{Ca}^{2+}\right]=1,44 \cdot 10^{-4} \mathrm{~mol}\right.$. $\mathrm{L}^{-1}$ ) until the color solution change from blue to pink for free di-HMBP and from green to brown for $\gamma \mathrm{Fe}_{2} \mathrm{O}_{3} @ \mathrm{di}$ HMBP particles solution. The variation of color is due to the complexation between EBT and calcium ions. Then the amount of calcium ions complexed with the HMBP functionality is deduced.

2.7. Magnetic Properties and Magnetic Resonance Imaging. The magnetic behavior of the as-synthesized nanoparticles is characterized using the MIAplex ${ }^{\mathrm{R}}$ reader (Magnisense). The MIAplex reader [13] measures the nonlinear response of the magnetic labels when they are exposed to a multifrequency alternating magnetic field. This specific signature [14] is based on $\mathrm{d}^{2} \mathrm{~B}(\mathrm{H}) / \mathrm{dH}^{2}$.

MR imaging of the test tubes was performed using a $4.7 \mathrm{~T}$ MR scanner (Bruker). For measurements of $\mathrm{T} 1$ relaxation times, axial spin echo (SE) sequences were obtained with TR values of $10,000 \mathrm{~ms}$ as well as TE of $16 \mathrm{~ms}$ at $4.7 \mathrm{~T}$. For measurements of $\mathrm{T} 2 *$ relaxation times, axial $\mathrm{T} 2 *$-weighted SE images were obtained with a TR of $800 \mathrm{~ms}$ and TE of $6.4 \mathrm{~ms}$ at $4.7 \mathrm{~T}$.

2.8. In Vitro Hydroxyapatite Targeting. The lyophilized hydroxyapatite [15] with a ratio $\mathrm{Ca} / \mathrm{P}$ equal to 1,64 . HA $(10 \mathrm{mg} / \mathrm{mL})$ was suspended in a 5 millimeter $\gamma \mathrm{Fe}_{2} \mathrm{O}_{3} @$ diHMBP sol $0,4 \mathrm{mg} / \mathrm{mL}\left(\mathrm{Fe}=5 \cdot 10^{-3} \mathrm{M}\right)$. Then nanoparticles are incubated and shaken with $\mathrm{HA}$ at $37^{\circ} \mathrm{C}$ during 24 hours. After filtration and water washing with a syringe filter with $0.45 \mu \mathrm{m}$ pore size, HA is resuspended in sol and lyophilized for infrared spectroscopy. The concentration of nanoparticles remained in the water suspension was measured by UV/VIS spectrophotometer at 350 and $480 \mathrm{~nm}$ for the calculation of the amount bound to HA.

2.9. Cell Viability. Human osteosarcoma cells (MG63) line was cultured in Dulbecco's modified Eagle's medium (DMEM, Invitrogen) supplemented with $10 \%$ calf serum. MG63 osteoblast-like cells used in the present study were obtained from the American Type Culture Collection (ATCC $\mathrm{N}^{\circ}$ CRL 1427).

Cell viability was evaluated using the MTT (3-(4,5Dimethylthiazol-2-yl)-2,5-diphenyltetrazolium bromide) assay at day 1 , day 3 , and day 5 . Cells were seeded at a density of $20 \times 10^{3}$ cells/well in 96-well flat-bottom plates (Falcon, Strasbourg, France) and incubated in complete culture medium for 1,3 , and 5 days. Then, medium was removed and replaced by $10 \%$ FCS-medium containing increasing concentrations $\gamma \mathrm{Fe}_{2} \mathrm{O}_{3} @$ di-HMBP nanocrystals. After 1, 3, and 5 days of incubation, cells were washed with phosphate buffered saline (PBS, Invitrogen) and incubated with $0.1 \mathrm{~mL}$ of MTT ( $2 \mathrm{mg} / \mathrm{mL}$, Sigma-Aldrich) for additional 4 hours at $37^{\circ} \mathrm{C}$. The insoluble product was then dissolved by addition of DMSO (Sigma-Aldrich). Optical density was measured at $570 \mathrm{~nm}$ using a Labsystems Multiscan MS microplate reader. Each in vitro experiment was performed three times, with four wells per sample per experiment.

2.10. Cell Labelling. The labeling of living cells is evaluated using Prussian blue staining for $\gamma \mathrm{Fe}_{2} \mathrm{O}_{3} @ \mathrm{di}-\mathrm{HMBP}$ nanocrystals. The principle of Prussian blue staining is that the ferric iron $\left(\mathrm{Fe}^{3+}\right)$ in the presence of ferrocyanide ion is precipitated as the highly colored and highly water-insoluble complex, potassium ferric ferrocyanide, Prussian blue. The cells were cultivated for 24 hours in eight-well chamber slides in the presence or not of $\gamma \mathrm{Fe}_{2} \mathrm{O}_{3} @$ di-HMBPs nanocrystals. The cells were then washed three times with PBS, fixed with acetone (10 minutes) and dried at room temperature for $20 \mathrm{mn}$. The attached cell monolayer was incubated with 5\% potassium ferrocyanide (5 minutes), washed with PBS and then incubated again with solution containing $5 \%$ potassium ferrocyanide and 10\% hydrochloric acid for 10 minutes and washed with distilled water three times. The iron particles in the cells were observed as blue dots using an optical microscope with phase contrast.

\section{Results and Discussion}

Nanoparticles functionalization plays a major role within nanotechnologies applications. Scheme 1 describes the procedure to design a new MRI nanoparticle for targeted drug delivery to bone. Small $\gamma \mathrm{Fe}_{2} \mathrm{O}_{3}$ nanocrystals were chosen for their superparamagnetic behavior and their high T2 contrast agent sensitivity for MRI. The 1,5-dihydroxy1,5,5-tris-phosphono-pentyl-phosphonic acid (di-HMBPs) was chosen for the two HMBP functionalities: one HMBP moiety as anchoring agent for $\gamma \mathrm{Fe}_{2} \mathrm{O}_{3}$ surface and the second as targeting function due to strong affinity for bone. Our approach requires the two HMBP functions of 


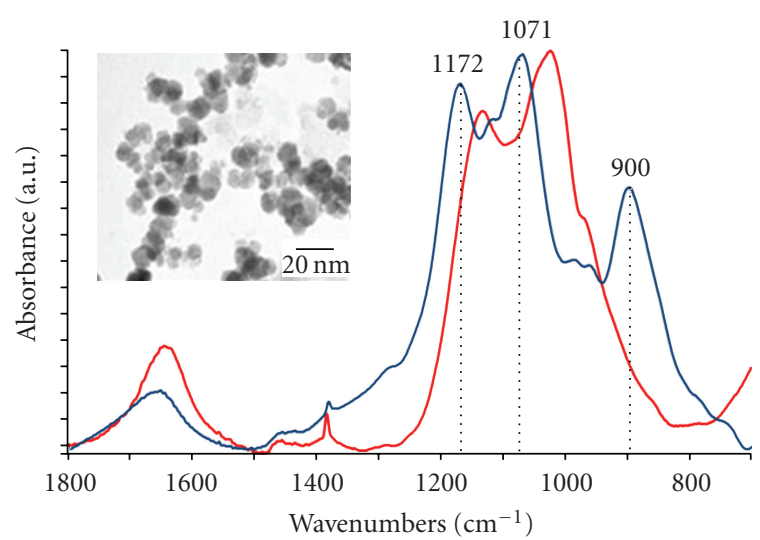

Figure 1: IR spectra of di-HMBP free molecules (blue curve) and $\gamma \mathrm{Fe}_{2} \mathrm{O}_{3} @$ di-HMBP (red curve). Insert: transmission electron microscopy image taken of a nanoparticle solution at $\mathrm{pH} 7$.

the molecule to be separated by a short spacer, to avoid the nanoparticles anchoring with the two HMBP moieties, leading to nanoparticles aggregation and lost of the specific bone targeting.

Maghemite $\gamma \mathrm{Fe}_{2} \mathrm{O}_{3}$ nanocrystals were prepared as described previously [16] by soft chemistry. At the end of the synthesis, a solution of di-HMBP in water at $\mathrm{pH} 4$ is added to the bare nanoparticle dispersion. The $\mathrm{pH}$ was then progressively increased to $\mathrm{pH} 7.4$ by the addition of sodium hydroxide $\mathrm{NaOH}$, thus achieving a stable dispersion of nanoparticles.

After dialysis, the dispersed solution is lyophilized. The powder is easily dispersed in water and the nanoparticles sols are stable over a broad range of $\mathrm{pH}(4-12)$ and concentration (over $40 \mathrm{wt} \%$ ), in suitable ionic strength $\left(<0.6 \mathrm{~mol} \cdot \mathrm{L}^{-1}\right)$ and in various biological buffers such as PBS and Hepes. The TEM image (insert Figure 1) of deposited nanocrystals indicates an average diameter and a polydispersity, respectively, equal to $11 \mathrm{~nm}$ and $20 \%$.

IR spectroscopy analysis (Figure 1) shows that the phosphonate groups are highly interaction with the nanoparticle surface.

For the free HMBP-COOH molecules (blue curve), within the $\mathrm{P}-\mathrm{O}$ stretching region $\left(1200-900 \mathrm{~cm}^{-1}\right)$, the spectrum exhibits two sharp peaks at 1172 and $900 \mathrm{~cm}^{-1}$, assigned to $\mathrm{P}=\mathrm{O}$ and $\mathrm{P}-\mathrm{OH}$, respectively [17]. The broad band at $1071 \mathrm{~cm}^{-1}$ is characteristic for the vibrational mode for the $\mathrm{PO}_{3}$ group [18].

Comparing the $\gamma \mathrm{Fe}_{2} \mathrm{O}_{3} @$ di-HMBP nanocrystals (red curve) with the free di-HMBP solution (blue curve), the large changes observed within the $\mathrm{P}-\mathrm{O}$ stretching region (1200-900 $\mathrm{cm}^{-1}$ ) show that a strong interaction between the phosphonate headgroup and the $\mathrm{Fe}_{2} \mathrm{O}_{3}$ surface is present. These results are consistent with phosphonate binding to the oxide surface [19] and we can suggest that the Fe atoms within the particle surface are coordinated by oxygen atoms from the phosphonate groups [20].

${ }^{31} \mathrm{P}$ NMR titration is used in order to quantify the average number of molecules per nanocrystal. An average number of $2100 \pm 100$ di-HMBP molecules per nanoparticle

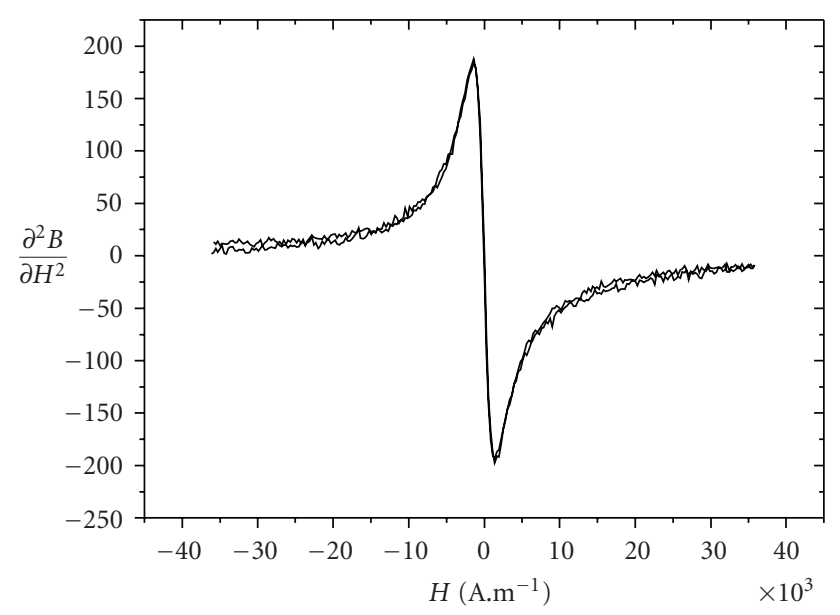

FIGURE 2: $\gamma \mathrm{Fe}_{2} \mathrm{O}_{3} @$ di-HMBP second derivative of the magnetization recorded at $\mathrm{pH} 7.4$, in $\mathrm{H}_{2} \mathrm{O}$ solutions.

is obtained, corresponding to 0.1 equivalent per $\mathrm{Fe}$ ions (around 0.3 per surface Fe ions).

Dynamic light scattering was used to characterize zeta potential and hydrodynamic diameter. This measurement is an indication of surface charge on a particulate species, which plays an important role in determining solution stability, susceptibility to aggregation and precipitation problems, as well as protein and cellular surface binding in vivo. At physiological pH, the $\gamma \mathrm{Fe}_{2} \mathrm{O}_{3} @$ di-HMBPs particles exhibit a negative zeta potential $(-54 \mathrm{mV})$ and a hydrodynamic diameter of $36 \mathrm{~nm}$ suggesting the presence of few aggregates (mean crystalline core of $11 \mathrm{~nm}$ ). The negative charge surface suggests the presence of free HMBP functionalities on the magnetic core of the particle (Scheme 1). To determine the number of free HMBP, we used standard procedures of colorimetric tests to deduce the number of calcium ions complexed per $\gamma \mathrm{Fe}_{2} \mathrm{O}_{3} @$ di-HMBP nanoparticles. For free diHMBP molecules, we found 3.8 calcium ions complexed per molecule meaning that each HMBP functionality may complex about 2 calcium ions. The amount of calcium ions complexed per nanoparticle is found equal to 3100 \pm 200 . Considering that each HMBP functionality may complex 2 calcium ions, an amount of 1550 free HMBP per nanoparticle is deduced. This result is consistent with NMR measurements leading to $2100 \mathrm{HMBP}$ per nanoparticle. Hence, the free HMBP functionalities at the outer of the nanoparticles surface should allow their bone targeting and the increase of bone mineral density.

The magnetic properties of these nanoparticles have been studied using a MIAplex ${ }^{\mathrm{R}}$ reader.

The second derivative of magnetization $\mathrm{d}^{2} \mathrm{~B}(\mathrm{H}) / \mathrm{dH}^{2}$ (Figure 2), presents one maxima and one minima with no hysteresis loop. This specific magnetic signature is characteristic of superparamagnetic behavior of particles with low dipolar interaction [21]. This superparamagnetic behavior allows to use these particles as contrast agent for MRI.

To investigate the MR signal enhancement effects, the aqueous as-prepared nanoparticles at different Fe concentrations were measured on a 4.7 T MRI scanner. As shown 


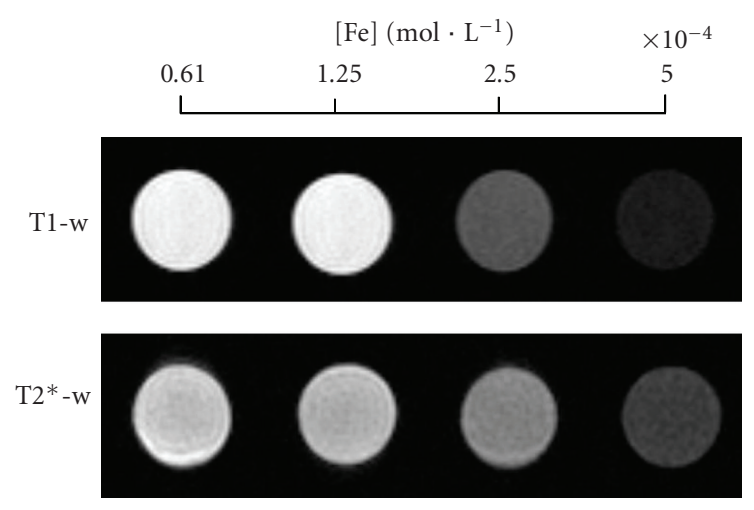

(a)

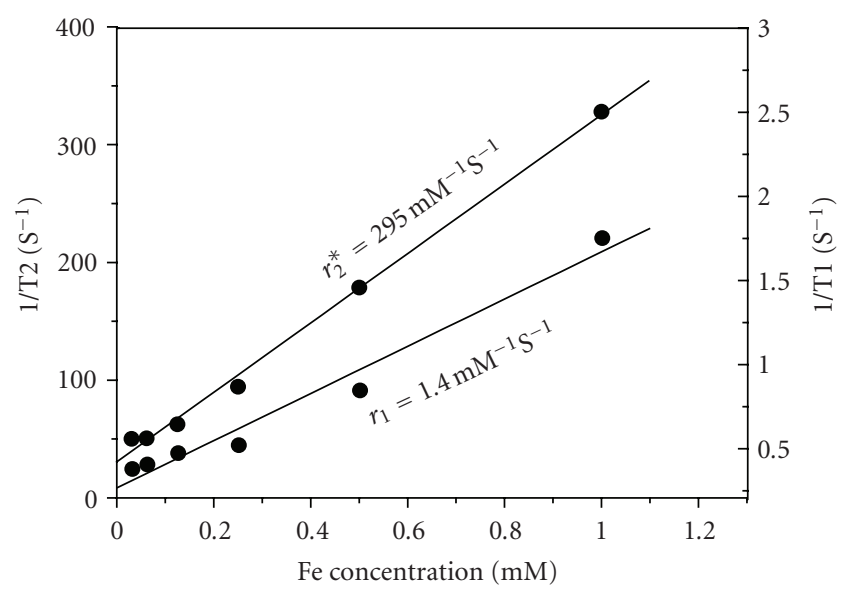

(b)

Figure 3: (a) T1 weight MR images and T2* weight MR images of aqueous solutions of as-synthesized nanoparticles at different Fe concentrations; (b) $\mathrm{T} 1$ and $\mathrm{T} 2 *$ relaxation rates $(1 / \mathrm{T} 1,1 / \mathrm{T} 2 *)$ plotted against the $\mathrm{Fe}$ concentration for the various aqueous solutions.

in Figure 3(a), both $\mathrm{T} 1$ and $\mathrm{T} 2 *$ weighted images change drastically in signal intensity with an increasing amount of nanoparticles, indicating that as synthesized nanoparticles generated MR contrast on both longitudinal (T1) and transverse $\left(\mathrm{T}_{2} *\right)$ proton relaxation times weighted sequences. Figure $3(\mathrm{~b})$ shows the relaxation rates $1 / \mathrm{T} 1$ and $1 / \mathrm{T} 2 *$ as a function of the iron concentration. The relaxation rates varied linearly with the iron concentration, as expected. The longitudinal $r_{1}$ and transverse $r_{2}{ }^{*}$ relaxivities (corresponding to the slopes of the lines) are found to be $1.40 \mathrm{Fe} \mathrm{mM}^{-1} \mathrm{~s}^{-1}$ and $295 \mathrm{Fe} \mathrm{mM}^{-1} \mathrm{~s}^{-1}$, respectively. Such values for $r_{1}$ and $r_{2}{ }^{*}$ suggest that HMBP coated nanoparticles can act as both $\mathrm{T} 1$ and $\mathrm{T} 2 *$ contrast agents taking into account their small size, but seem to be more favourable as $\mathrm{T} 2{ }^{*}$ contrast agents due to their much larger $r_{2}{ }^{*}$ value.

One of the factors that makes HMBP most potent BP drugs is its high skeletal uptake and retention, which is directly related to its affinity towards hydroxyapatite [22] (HA). To demonstrate the specific targeting of $\gamma \mathrm{Fe}_{2} \mathrm{O}_{3} @ \mathrm{di}-$ HMPBs nanocrystals to bone, standard in vitro assay [12] were performed to demonstrate the strong affinity

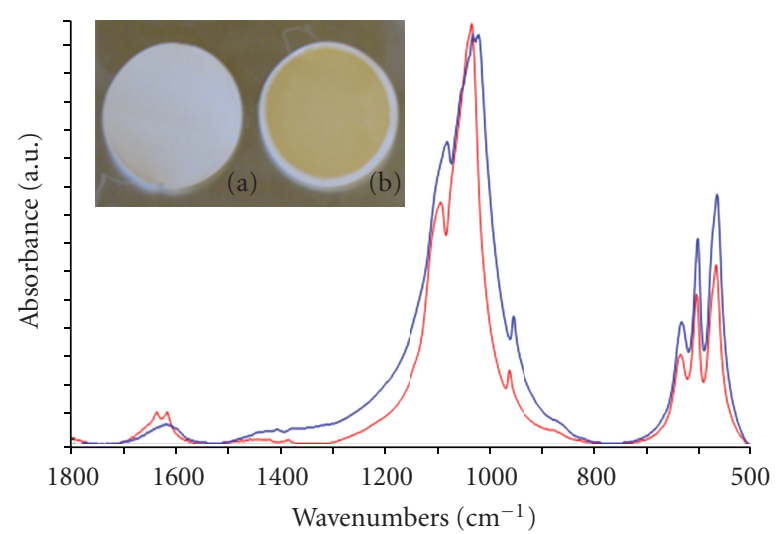

FIGURE 4: IR spectra of HA (red curve) and HA incubated with $\gamma \mathrm{Fe}_{2} \mathrm{O}_{3} @$ di-HMBP (blue curve) for 24 hours and separated from free nanoparticules. Insert: optical image taken from HA (a) and $\mathrm{HA}$ incubated with $\gamma \mathrm{Fe}_{2} \mathrm{O}_{3} @ \mathrm{di}-\mathrm{HMBP}(\mathrm{b})$.

of those new MRI contrast agent with hydroxyapatite. A $\gamma \mathrm{Fe}_{2} \mathrm{O}_{3} @$ diHMBP sol $\left([\mathrm{Fe}]=5 \cdot 10^{-3} \mathrm{M}\right)$ have been incubated with $\mathrm{HA}$ at $37^{\circ} \mathrm{C}$, and then separated and washed using a $0.45 \mu \mathrm{m}$ filter. The binding capacity of the assynthesized nanocomplexes has been studied using UV-vis and infrared (Figure 4) spectroscopies. As shown insert Figure 4, the change of HA color from white to brown indicates $\gamma \mathrm{Fe}_{2} \mathrm{O}_{3} @$ di-HMBPs binds HA with very high affinity due to the high amount of iron nanoparticles within HA. The concentration of nanoparticles remained in the water suspension was measured by UV-vis spectrophotometer at 350 and $480 \mathrm{~nm}$ for the calculation of the amount bound to HA. The deduced bound amount is equal to $0.05 \pm$ $0.01 \mathrm{mg}$ of nanoparticles per mg of HA (eq. $0.19 \mathrm{mM} \mathrm{HMBP}$ per mgHA). Figure 4 displays the IR spectrum of HA (blue curve) and incubated HA with $\gamma \mathrm{Fe}_{2} \mathrm{O}_{3} @$ diHMBP nanoparticles (red curve).

The HA spectrum (red curve) exhibits different bands between $1250-600 \mathrm{~cm}^{-1}$ that are characteristic of the $\mathrm{P}-\mathrm{O}$ stretching region within HA [10]. For the HA nanocomplex, the analysis of the $\mathrm{P}-\mathrm{O}$ stretching region is complicated due to strong background absorbance of the HA matrix $(\nu(\mathrm{PO} 4))$ [23]. The HA incubated with $\gamma \mathrm{Fe}_{2} \mathrm{O}_{3} @$ di-HMBP (blue curve), the $\mathrm{P}-\mathrm{O}$ stretching region is broadened compared to initial HA. This is very difficult to clearly assign this effect. Obviously, more experiments are needed to elucidate the exact mechanism of nanoparticle surface bonding on HA.

The magnemite nanocrystals deduced from UV-vis spectroscopy and the brown color (insert Figure 4) of incubated HA with $\gamma \mathrm{Fe}_{2} \mathrm{O}_{3} @$ di-HMBP nanocrystals are suggesting selective interaction of the nanocomplex with HA and then potential targeting to bone.

In order to assess cell viability we performed viability tests on osteosarcoma MG-63 cells, a cancer line, but a pertinent model to study efficiently the behavior of osteoblastic cell line [24]. The as-synthesized nanocrystals were incubated with MG63 osteosarcoma cells precultured for 24 hours, 3 days and 5 days for various extra cellular 


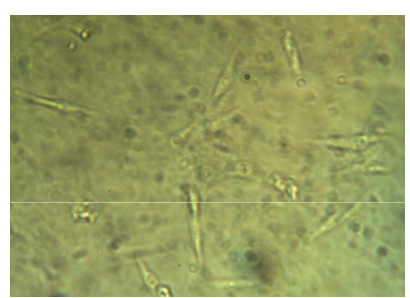

(a)

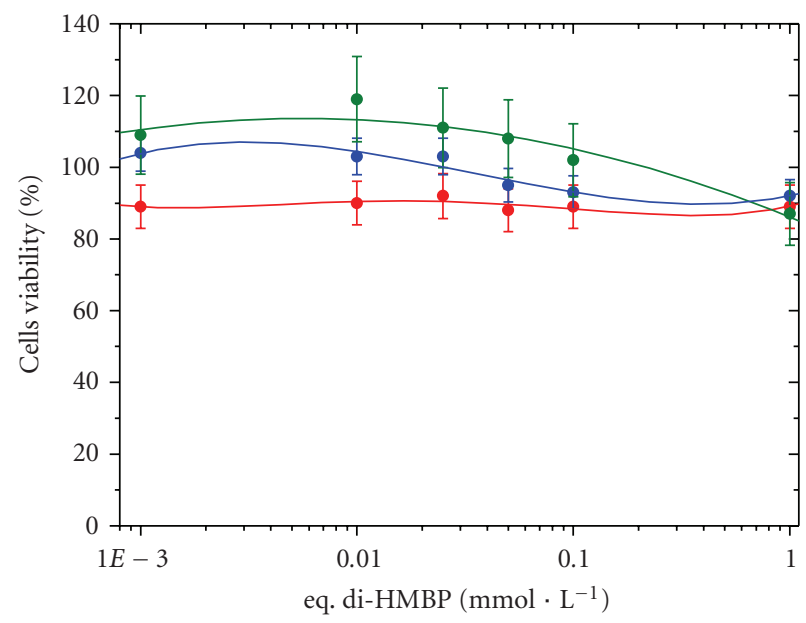

(c)

Figure 5: Optical blue prussian images of MG63 cells control (a) and MG63 cells incubating 24 hours with $\gamma \mathrm{Fe}_{2} \mathrm{O}_{3} @$ di-HMBPs at $100 \mu \mathrm{M}$ (b). Comparative effects of $\gamma \mathrm{Fe}_{2} \mathrm{O}_{3} @$ di-HMBPs on MG-63 osteoblast cells proliferation (c) for 24 hours, (red curve), 3 days (blue curve) and 5 days (green curve).

iron concentrations up to $3 \mathrm{mmol} \cdot \mathrm{L}^{-1}\left(1 \mathrm{eq} \cdot \mathrm{mmol} \cdot \mathrm{L}^{-1}\right.$ diHMBP). The proliferation of MG63 cells was indicated by the MTT assay as shown in Figure 5).

For the three times of incubation, MTT proliferation assay showed normal growth of osteoblast cells. No cytoxicity was observed. To determine the intracellular uptake of $\gamma \mathrm{Fe}_{2} \mathrm{O}_{3} @$ di-HMBPs nanocrystals, blue prussian imaging was performed on human MG63 cells (Figures 5(a) and $5(b))$. The iron particles into the cells were observed as blue dots using an optical microscope with phase contrast (Figure 5(b)). This picture indicates massive and uniform internalization of nanocrystals within the cells. Hence, the $\gamma \mathrm{Fe}_{2} \mathrm{O}_{3} @$ di-HMBPs nanocrystals may act as a diagnostic and therapeutic system. A full biological study is in progress to understand the mechanism of such nanoparticles for osteoporosis treatment and diagnostic. The aim of this work is to describe influences of nanoparticles on protein expression patterns related to the differentiation and mineralization of bone-forming cells, viability, remodeling of cell architecture, cell adhesion, and assembly of extracellular matrix in human normal cells.

\section{Conclusion}

A bone-targeted MRI contrast agent have been designed with superparamagnetic nanoparticles and bisphosphonate moieties. HMBP functionalities exhibits highly iron and calcium complexing effects. To test feasibility of such nanosystem, this system have been complexed to hydroxyapatite to demonstrate bone targeting and increasing bone mineral density to reduce the incidence of major osteoporotic fracture. Moreover, the superparamagnetic behavior of such nanoparticle allows them to be used as MRI contrast agent in order to improve the therapeutic diagnostic for osteoporosis.

\section{Acknowledgments}

The authors thank Dr. S. Sarda and Dr. C. Rey (CIRIMATUMR CNRS 5085) for providing them hydroxyapatite, Dr. S. Changotade for providing them osteoblastic cells and Pr. D. Lutomski (CSPBAT-FRE CNRS 3043) for fruitful discussions about bone targeting and specific steps of osteogenic differentiation (work in progress). This work was supported in part by Magnisense Company.

\section{References}

[1] T. J. Martin and V. Grill, "Bisphosphonates-mechanisms of action," Australian Prescriber, vol. 23, no. 6, pp. 130-132, 2000.

[2] J. Soltau and J. Drevs, "The role of bisphosphonates in oncology," Drugs of the Future, vol. 29, no. 9, pp. 911-921, 2004.

[3] J. E. Fisher, M. J. Rogers, J. M. Halasy, S. P. Luckman, D. E. Hughes, P. J. Masarachia, G. Wesolowski, R. G. G. Russell, G. A. Rodan, and A. A. Reszka, "Alendronate mechanism of action: geranylgeraniol, an intermediate in the mevalonate pathway, prevents inhibition of osteoclast formation, bone resorption, and kinase activation in vitro," Proceedings of the National Academy of Sciences of the United States of America, vol. 96, no. 1, pp. 133-138, 1999.

[4] J. S. Bauer and T. M. Link, "Advances in osteoporosis imaging," European Journal of Radiology, vol. 71, no. 3, pp. 440-449, 2009.

[5] R. Lawaczeck, M. Menzel, and H. Pietsch, "Superparamagnetic iron oxide particles: contrast media for magnetic resonance imaging," Applied Organometallic Chemistry, vol. 18, no. 10, pp. 506-513, 2004.

[6] C. C. Berry, "Progress in functionalization of magnetic nanoparticles for applications in biomedicine," Journal of Physics D, vol. 42, no. 22, 2009.

[7] T. K. Jain, M. K. Reddy, M. A. Morales, D. L. LesliePelecky, and V. Labhasetwar, "Biodistribution, clearance, and biocompatibility of iron oxide magnetic nanoparticles in rats," Molecular Pharmaceutics, vol. 5, no. 2, pp. 316-327, 2008.

[8] Y. Lalatonne, C. Paris, J. M. Serfaty, P. Weinmann, M. Lecouvey, and L. Motte, "Bis-phosphonates-ultra small superparamagnetic iron oxide nanoparticles: a platform towards diagnosis and therapy," Chemical Communications, no. 22, pp. 2553-2555, 2008.

[9] F. Benyettou, Y. Lalatonne, O. Sainte-Catherine, M. Monteil, and L. Motte, "Superparamagnetic nanovector with anticancer properties: $\gamma \mathrm{Fe}_{2} \mathrm{O}_{3} @ Z$ Zoledronate," International Journal of Pharmaceutics, vol. 379, no. 2, pp. 324-327, 2009.

[10] D. Portet, B. Denizot, E. Rump, F. Hindre, J.-J. Le Jeune, and P. Jallet, "Comparative biodistribution of thin-coated iron oxide nanoparticles TCION: effect of different bisphosphonate coatings," Drug Development Research, vol. 54, no. 4, pp. 173181, 2001. 
[11] I. Fishbein, I. S. Alferiev, O. Nyanguile, R. Gaster, J. M. Vohs, G. S. Wong, H. Felderman, I.-W. Chen, H. Choi, R. L. Wilensky, and R. J. Levy, "Bisphosphonate-mediated gene vector delivery from the metal surfaces of stents," Proceedings of the National Academy of Sciences of the United States of America, vol. 103, no. 1, pp. 159-164, 2006.

[12] M. Lecouvey, I. Mallard, T. Bailly, R. Burgada, and Y. Leroux, "A mild and efficient one-pot synthesis of 1hydroxymethylene-1,1-bisphosphonic acids. Preparation of new tripod ligands," Tetrahedron Letters, vol. 42, no. 48, pp. 8475-8478, 2001.

[13] P. I. Nikitin and P. M. Vetoshko, Patent of Russian Federation RU 2166751, 2000, EP 1262766 publication, 2002.

[14] L. Lenglet, "Multiparametric magnetic immunoassays utilizing non-linear signatures of magnetic labels," Journal of Magnetism and Magnetic Materials, vol. 321, no. 10, pp. 16391643, 2009.

[15] F. Errassifi, A. Barroug, S. Sarda, C. Rey, A. Lebugle, and A. Legrouri, "Etude de l'interaction du risedronate avec un phosphate de calcium analogue au minéral osseux," in Proceedings of the 2 nd International Conference on the Valorization of Phosphates and Phosphorous Compounds, vol. 4, pp. 293300, 2006.

[16] Y. Lalatonne, L. Motte, V. Russier, A. T. Ngo, P. Bonville, and M. P. Pileni, "Mesoscopic structures of nanocrystals: collective magnetic properties due to the alignment of nanocrystals," Journal of Physical Chemistry B, vol. 108, no. 6, pp. 1848-1854, 2004.

[17] R. D. Peacock, "The intensities of lantahnide f-f transitions," Structure and Bonding, vol. 22, pp. 83-122, 1975.

[18] E. Podstawka, R. Borszowska, M. Grabowska, M. Drạg, P. Kafarski, and L. M. Proniewicz, "Investigation of molecular structures and adsorption mechanisms of phosphonodipeptides by surface-enhanced Raman, Raman, and infrared spectroscopies," Surface Science, vol. 599, no. 1-3, pp. 207-220, 2005.

[19] K. V. P. M. Shafi, A. Ulman, X. Yan, et al., "Sonochemical synthesis of functionalized amorphous iron oxide nanoparticles," Langmuir, vol. 17, no. 16, pp. 5093-5097, 2001.

[20] W. Gao, L. Dickinson, C. Grozinger, F. G. Morin, and L. Reven, "Self-assembled monolayers of alkylphosphonic acids on metal oxides," Langmuir, vol. 12, no. 26, pp. 6429-6435, 1996.

[21] Y. Lalatonne, F. Benyettou, D. Bonnin, N. Lièvre, P. Monod, M. Lecouvey, P. Weinmann, and L. Motte, "Characterization of magnetic labels for bioassays," Journal of Magnetism and Magnetic Materials, vol. 321, no. 10, pp. 1653-1657, 2009.

[22] G. H. Nancollas, R. Tang, R. J. Phipps, Z. Henneman, S. Gulde, W. Wu, A. Mangood, R. G. G. Russell, and F. H. Ebetino, "Novel insights into actions of bisphosphonates on bone: differences in interactions with hydroxyapatite," Bone, vol. 38, no. 5, pp. 617-627, 2006.

[23] S. C. D’Andrea and A. Y. Fadeev, "Covalent surface modification of calcium hydroxyapatite using $n$-alkyl- and $n$ fluoroalkylphosphonic acids," Langmuir, vol. 19, no. 19, pp. 7904-7910, 2003.

[24] L. C. Hofbauer, F. Gori, B. L. Riggs, D. L. Lacey, C. R. Dunstan, T. C. Spelsberg, and S. Khosla, "Stimulation of osteoprotegerin ligand and inhibition of osteoprotegerin production by glucocorticoids in human osteoblastic lineage cells: potential paracrine mechanisms of glucocorticoid-induced osteoporosis," Endocrinology, vol. 140, no. 10, pp. 4382-4389, 1999. 


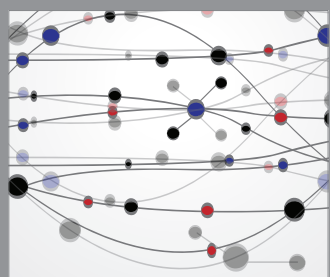

The Scientific World Journal
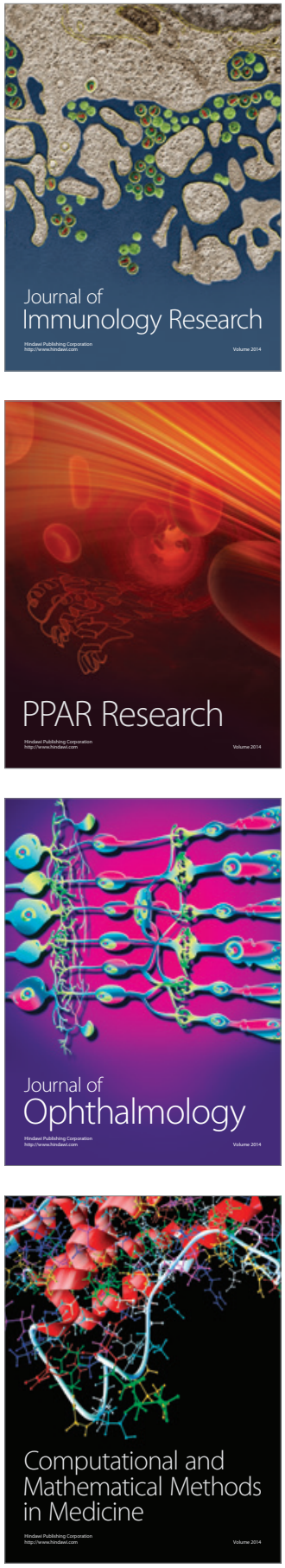

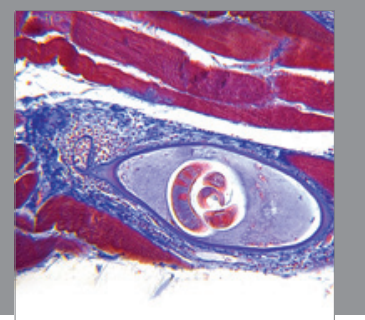

Gastroenterology

Research and Practice
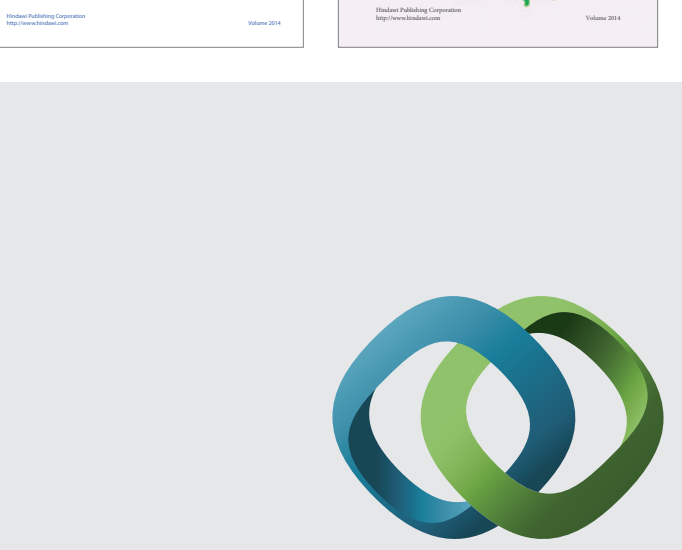

\section{Hindawi}

Submit your manuscripts at

http://www.hindawi.com
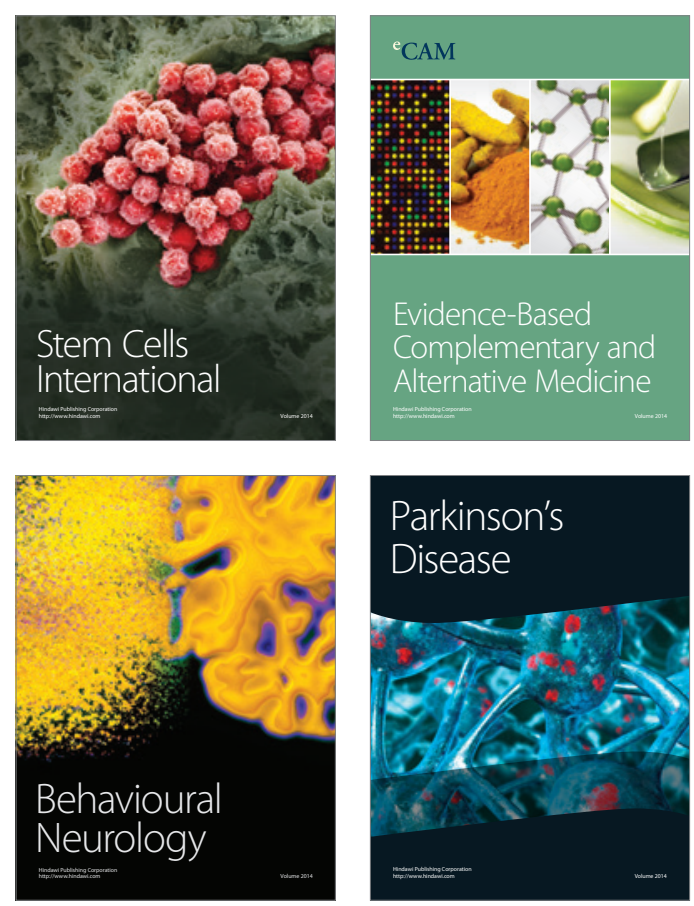

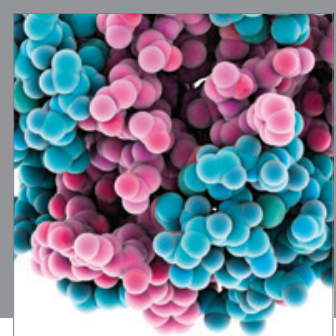

Journal of
Diabetes Research

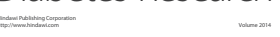

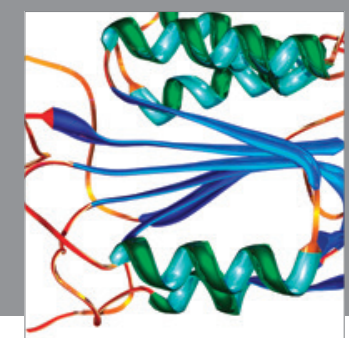

Disease Markers
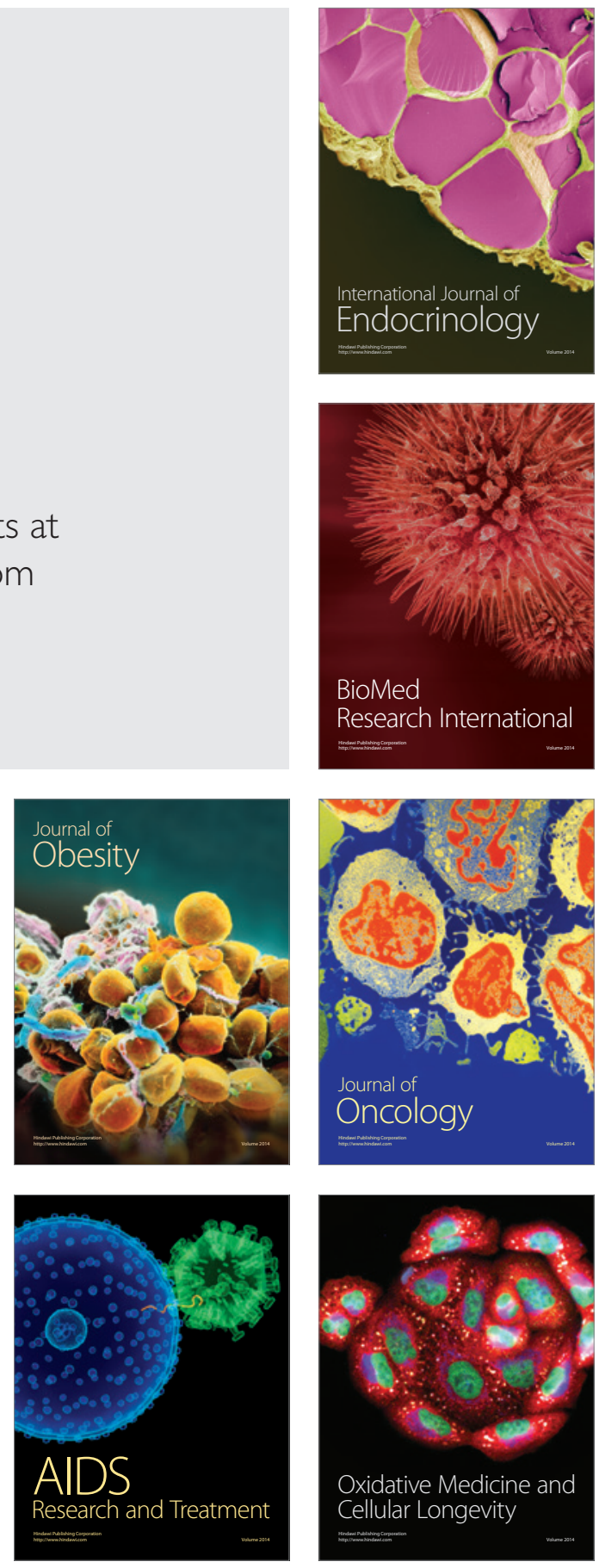